\title{
Paracetamol in the environment and its degradation by microorganisms
}

\author{
Shijin Wu $\cdot$ Lili Zhang $•$ Jianmeng Chen
}

Received: 27 July 2012 /Revised: 29 August 2012 / Accepted: 3 September 2012 / Published online: 4 October 2012

(C) Springer-Verlag Berlin Heidelberg 2012

\begin{abstract}
Paracetamol (4'-hydroxyacetanilide, $N$-acetyl- $p$ aminophenol, acetaminophen, and paracetamol) is a widely used over-the-counter analgesic and antipyretic drug. Paracetamol and structural analogs are ubiquitous in the natural environment and easily accumulate in aquatic environment, which have been detected in surface waters, wastewater, and drinking water throughout the world. Paracetamol wastewater is mainly treated by chemical oxidation processes. Although these chemical methods may be available for treating these pollutants, the harsh reaction conditions, the generation of secondary pollutants, and the high operational cost associated with these methods have often made them not a desirable choice. Biodegradation of paracetamol is being considered as an environmentally friendly and low-cost option. The goal of this review is to provide an outline of the current knowledge of biodegradation of paracetamol in the occurrence, degrading bacteria, and proposed metabolic/ biodegrading pathways, enzymes and possible intermediates. The comprehensive understanding of the metabolic pathways and enzyme systems involved in the utilization of paracetamol means will be helpful for optimizing and allowing rational design of biodegradation systems for paracetamol-contaminated wastewater.
\end{abstract}

Keywords Paracetamol (acetaminophen) - Structural analogs $\cdot$ Metabolic/biodegrading pathway

\footnotetext{
$\mathrm{S}$. Wu $\cdot$ J. Chen $(\triangle)$

College of Biological and Environmental Engineering,

Zhejiang University of Technology,

Hangzhou 310032, People's Republic of China

e-mail: jchen@zjut.edu.cn

\section{Zhang}

State Key Laboratory of Environmental Aquatic Chemistry, Research Center for Eco-Environmental Sciences, Chinese Academy of Sciences,

Beijing 100085, China
}

\section{Introduction}

Pharmaceuticals and their metabolites are subclasses of organic contaminants that have been detected in wastewater and surface waters throughout the world (Benotti et al. 2009; Philips et al. 2010). These emerging pollutants are continuously introduced into the aquatic environment by several emissions from manufacturing facilities, consumer use and disposal, and hospital waste (Langford and Thomas 2009; Thomas and Langford 2007; Philips et al. 2010). Even though the detected concentrations are typically in the nanogram- to microgram-per-liter range, it cannot be excluded that molecules designed to be biologically active affect sensitive aquatic organisms even at such low concentrations (Huber et al. 2005). A variety of potential adverse effects, including acute and chronic damage, accumulation in tissues, reproductive damage, inhibition of cell proliferation, and behavioral changes, have been documented in these low levels (Philips et al. 2010; Escher et al. 2011). Currently, very little data exist on the levels of pharmaceuticals in the environment.

The most prevalent pharmaceuticals in treated wastewater are typically those that are most frequently prescribed or purchased over the counter, such as a series of substituted acetanilides including paracetamol and structural analogs or their possible intermediates. Paracetamol, also known as 4acetaminophenol, IUPAC name $N$-(4-hydroxyphenyl)ethanamide, is a very common over-the-counter analgesic used for fever, headaches, and other minor pain. Paracetamol consists of a benzene ring core substituted by one hydroxyl group and the nitrogen atom of an amide group in the para $(1,4)$ pattern (Bales et al. 1985). As part of the class of drugs known as "aniline analgesics," paracetamol is the only such drug still in use today. Paracetamol and structural analogs are depicted in Fig. 1.

The pharmacological effects of paracetamol are generally considered to be based on inhibition of prostaglandin synthesis (Malmberg and Yaksh 1982). In fact, the mechanism of 
Fig. 1 Paracetamol and structural analogs

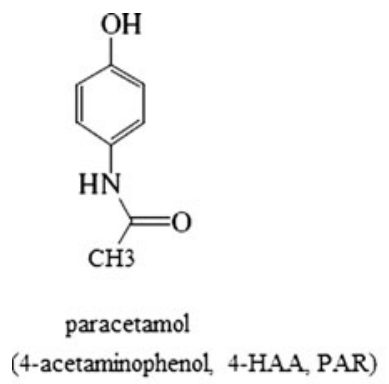

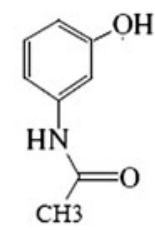

3'-HAA

(3'-hydroxyacetanilide)

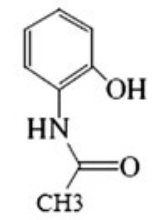

2'-HAA

(2'-hydroxyacetanilide)

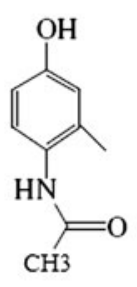

2-CH2-PAR<smiles>CC(=O)Nc1ccc(O)c(C)c1</smiles>

3-CH2-PAR<smiles>O=C(Nc1ccc(O)cc1)C(F)(F)F</smiles>

CF3-4-H.AA

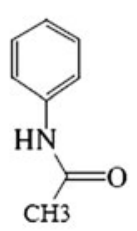

Acetanilid<smiles>CCOc1ccc(NC(C)=O)cc1</smiles>

Phenacetin(4-acetophenetidine)<smiles>CCN(CC)CC(=O)Oc1ccc(NC(C)=O)cc1</smiles>

Propacetamol action of paracetamol is not completely understood till now. The main mechanism proposed is the inhibition of cyclooxygenase, and recent findings suggest that it is highly selective for COX-2. At therapeutic levels, paracetamol is considered to be safe for humans upon normal drug use (Thomas 1993). The absorption of low therapeutic doses of paracetamol is usually rapid and complete; the systemic bioavailability and the plasma half-life being about $75 \%$ at 1.5 to $2.5 \mathrm{~h}$, respectively.

Frequent occurrence of paracetamol in aquatic environments and drinking water has raised a concern about their potential effects on environment and human health. Paracetamol is ranked as one of the top three drugs prescribed in England and is one of the top 200 prescriptions in the USA (Sebastine and Wakeman 2003; Zhang et al. 2008). In 2002, the USA produced $3.6 \times 10^{9} \mathrm{~g}$ of paracetamol (Bedner and Maccrehan 2006). In 1998, it was estimated that $3.2 \times 10^{9}$ tablets were consumed in the UK alone (Bessems and Vermeulen 2001). Paracetamol and their metabolites are continuously introduced into the aquatic environment by consumer use and disposal and hospital waste (Langford and Thomas 2009; Philips et al. 2010). Even paracetamol that is not highly persistent in the environment can be found at elevated concentrations and causes negative ecological effects because its continuous introduction into the environment can overwhelm its high transformation rates (Petrovic et al. 2003). 4Aminophenol is the hydrolytic product of acetaminophen (paracetamol) and is reported to have significant nephrotoxicity and teratogenic effects and has been detected as a synthetic intermediate (Sumera et al. 2006). Muir et al. (1997) have demonstrated that $58-68 \%$ of paracetamol and their metabolites are excreted from the body during therapeutic use.

Numerous studies have demonstrated that microorganisms play the major roles in the paracetamol degradation in the environment under various conditions, which has been reported by $\mathrm{Hu}$ et al. (2012). This paper is focused on summarizing the studies on paracetamol biodegradation, mainly in the last decade, in the following aspects: paracetamol in the occurrence, degrading bacteria, and proposed metabolic/biodegrading pathways in animals or microorganisms, enzymes, and possible intermediates.

\section{Paracetamol in the environment}

Paracetamol consumption throughout the world has increased. In the Nordic countries, usage increased fivefold between 1978 and 1988, and in 1994-1995, the rates in some developed countries exceeded $20 \mathrm{~g} / \mathrm{person} / \mathrm{year}$ (Sheen et al. 2002). Paracetamol was dispensed in 2006 in Wales (population approximately three million) at the level of over 140 tons, more than $45 \mathrm{~g} /$ person/year (Jones et al. 2007; Verlicchi et al. 2010). In the UK, approximately $3.2 \times$ 
$10^{9}$ tablets of paracetamol are consumed every year, which is an average of 55 tablets/person (Jones 1998). Paracetamol are easily accumulated in aquatic environment due to their high solubility and hydrophilicity, which have been detected in surface waters, wastewater, and drinking water throughout the world. Paracetamol is known to occur at high microgram per liter concentrations in influents and is, for the most part, effectively eliminated by wastewater treatment plants (WWTPs) (Thomas et al. 2007). It has been found with a concentration of up to $6 \mu \mathrm{gL}^{-1}$ in European sewage effluents (Ternes 1998), up to $10 \mu \mathrm{gL}^{-1}$ in US natural waters (Kolpin et al. 2002), and more than $65 \mu \mathrm{gL}^{-1}$ in Tyne River in the UK (Robert and Thomas 2006). In hospital effluents and WWTPs influents, paracetamol concentrations can exceed $150 \mu \mathrm{gL}^{-1}$; however, effective elimination by WWTPs often results in low nanogram per liter concentrations being detected in WWTPs discharges. In a 2002 survey of 139 US streams, Kolpin et al. (2002) detected acetaminophen in roughly $25 \%$ of the samples tested at a median concentration of $0.11 \mu \mathrm{gL}^{-1}$. The median concentration of paracetamol detected in surface waters is $0.055 \pm 0.051 \mu \mathrm{gL}^{-1}$ (Wiegel et al. 2004; Bound and Voulvoulis 2006; Gros et al. 2006). In raw wastewater, paracetamol was detected at a median concentration of $48 \pm 75 \mu \mathrm{gL}^{-1}$ (Han et al. 2006; Gomez et al. 2007). The median concentration of paracetamol detected in finished wastewater is $0.76 \pm 0.96 \mu \mathrm{gL}^{-1}$ (Gros et al. 2006; Han et al. 2006; Gomez et al. 2007).

The widespread use of acetaminophen raises the concern of whether or not the compound persists during treatment of wastewater and drinking water. One of the most common treatment processes in water utilities is chlorination. Bedner and Maccrehan (2006) reported that, during chlorination of acetaminophen, 11 different chlorination products were observed, including the toxic substances $N$-acetyl- $p$-benzoquinone imine (NAPQI) and 1,4-benzoquinone. Although these toxicants may exist only at very low levels in drinking water and wastewater, their presence along with multiple other pharmaceuticals deserves further consideration (Bedner and Maccrehan 2006). Table 1 summarizes the occurrence of paracetamol and the range of concentrations detected in water samples.

\section{Biodegradation of paracetamol by pure culture}

Nowadays, paracetamol wastewater is mainly treated by chemical oxidation processes such as electrochemical (Brillas et al. 2005), ozonation (Andreozzi et al. 2003), $\mathrm{H}_{2} \mathrm{O}_{2} / \mathrm{UV}$ oxidation (Andreozzi et al. 2003; Skoumal et al. 2006), $\mathrm{TiO}_{2}$ photocatalysis (Yang et al. 2008, 2009), and solar photoelectro-Fenton oxidation (Li et al. 2007). Although these chemical methods may be available for treating these pollutants, the harsh reaction conditions, the generation of secondary pollutants, and the high operational cost associated with these methods have often made them not a desirable choice (Li et al. 2007; Chen et al. 2010). Biodegradation of pharmaceutical compounds is being considered as an environmentally friendly and low-cost option and has been demonstrated to have the potential to eliminate pharmaceuticals by degrading them into innocuous end products such as $\mathrm{CO}_{2}$ and $\mathrm{H}_{2} \mathrm{O}$ (Hasan et al. 2011; Chen et al. 2010). However, little information is available about the biodegradation of paracetamol compared to other pharmaceutical compounds.

A mould which was isolated from a solution of paracetamol was identified as a Penicillium species and was found to possess the ability to utilize a series of substituted acetanilides, including paracetamol (4-hydroxyacetanilide), phenacetin (4-ethoxyacetanilide), and metacetamol (3hydroxyacetanilide) as sole carbon sources for growth (Hart and Orr 1975). Microorganisms have established effective strategies involving specialized enzyme systems and metabolic pathways to access paracetamol as a carbon and energy source. Thus, such microorganisms are capable of degrading paracetamol and converting them to easily metabolizable substrates. In addition, in-depth characterization of genes and enzyme systems involved in the utilization of paracetamol has led to an improved understanding of microbial paracetamol metabolism. A large number of

Table 1 Paracetamol occurrence in the environment (in micrograms per liter)

\begin{tabular}{llll}
\hline Surface water & Raw wastewater & Finished wastewater & Finished drinking water \\
\hline$<0.1$ (Stackelberg et al. 2004) & $0-0.26$ (Han et al. 2006) & $0-6.0$ (Ternes 1998) & Low ppb levels (Han et al. \\
& & & 2006) \\
0.11 (Kolpin et al. 2002) & $29-246$ (Gomez et al. 2007) & $0-0.16$ (Han et al. 2006) & 1.9 (Brun et al. 2006) \\
$0-0.026$ (Boyd and Furlong 2002) & $0.13-26$ (Gros et al. 2006) & $0-4.3$ (Gomez et al. 2007) \\
$0-0.25$ (Gros et al. 2006) & $1.2-10$ (Kolpin et al. 2002) & $0-5.99$ (Gros et al. 2006) \\
$0.52-0.56$ (Bound and Voulvoulis 2006) & $22-65$ (Robert and Thomas 2006) & $0.048-0.418$ (Radjenovic et al. 2007) \\
$0.007-0.066$ (Wiegel et al. 2004) & 6 (Ternes 1998) & $0.079-0.22$ (Bound and Voulvoulis \\
& 10 (Kolpin et al. 2002) & $2006)$ \\
\hline
\end{tabular}


Table 2 Bacterial strains capable of utilizing paracetamol as a sole carbon source

\begin{tabular}{|c|c|c|c|c|}
\hline Species, strain & Isolated from & $\begin{array}{l}\text { Concentration } \\
\left(\mathrm{mgL}^{-1}\right)\end{array}$ & Performance & References \\
\hline Stenotrophomonas sp. f1 & $\begin{array}{l}\text { Paracetamol-degrading aerobic } \\
\text { aggregate }\end{array}$ & 400 & Completely degradation in $116 \mathrm{~h}$ & Zhang et al. (2012) \\
\hline Pseudomonas sp. $\mathrm{f} 2$ & $\begin{array}{l}\text { Paracetamol-degrading aerobic } \\
\text { aggregate }\end{array}$ & 2,500 & Completely degradation in $70 \mathrm{~h}$ & Zhang et al. (2012) \\
\hline Pseudomonas sp. fg-2 & $\begin{array}{l}\text { Paracetamol-degrading aerobic } \\
\text { aggregate }\end{array}$ & 2,000 & Completely degradation in $45 \mathrm{~h}$ & Zhang et al. (2012) \\
\hline Delftia tsuruhatensis & In a membrane bioreactor biomass & 100 & $\begin{array}{l}\text { Shaking flask, } 97 \% \text { degraded in } \\
48 \mathrm{~h}\end{array}$ & Bart et al. (2011) \\
\hline $\begin{array}{l}\text { Pseudomonas } \\
\text { aeruginosa }\end{array}$ & In a membrane bioreactor biomass & 16 & $\begin{array}{l}\text { Shaking flask, } 40 \% \text { degraded in } \\
48 \mathrm{~h}\end{array}$ & Bart et al. (2011) \\
\hline Penicillium species & An acidic solution of paracetamol & $0.01 \%(w / v)$ & $\begin{array}{l}\text { Shaking flask, } 98 \% \text { degraded in } \\
36 \mathrm{~h}\end{array}$ & Hart and Orr (1975) \\
\hline Strain P1(unidentified) & An enrichment cultured consortium & 1,000 & $96.3 \%$ degraded in $20 \mathrm{~h}$ & Xu et al. (2003) \\
\hline Cupriavidus necator F1 & Activated sludge samples & 400 & Completely degradation in $48 \mathrm{~h}$ & Wei et al. (2011) \\
\hline Burkholderia sp. AK-5 & Rice field soil (4-aminophenol) & 2,140 & $\begin{array}{l}\text { Shaking flask, } 99 \% \text { degraded in } \\
15 \mathrm{~h}\end{array}$ & Murakami et al. (2003) \\
\hline Pseudomonas sp. ST-4 & $\begin{array}{l}\text { Activated sludge samples } \\
\text { (4-aminophenol as substrates) }\end{array}$ & $200 \mathrm{ppm}$ & $\begin{array}{l}\text { Shaking flask, } 80 \% \text { degraded in } \\
72 \mathrm{~h}\end{array}$ & Sumera et al. (2006) \\
\hline Pseudomonas sp. AP-3 & $\begin{array}{l}\text { Activated sludge samples } \\
\text { (2-aminophenol as substrates) }\end{array}$ & $340 \mathrm{ppm}$ & $\begin{array}{l}\text { Shaking flask, } 70 \% \text { degraded in } \\
48 \mathrm{~h}\end{array}$ & Takenaka et al. (1997) \\
\hline
\end{tabular}

microorganisms belonging to the phyla of eubacteria, yeast, and fungi and also some algae capable of using paracetamol as carbon and energy source have been described. A listing of isolated bacterial strains characterized for the degradation of those paracetamols is presented in Table 2.

The utilization of paracetamol and phenacetin as nitrogen sources by Penicillium species has been studied by Hart and Orr (1975), while Betz and Clarke (1973) showed that strains of Pseudomonas putida, Pseudomonas cepacia, and Pseudomonas acidovorans could grow in a mineral salts medium with acetamide or phenylacetamide as the carbon or nitrogen source.

Bart et al. (2011) reported that two paracetamol-degrading strains were isolated from the MBR biomass and identified as Delftia tsuruhatensis and Pseudomonas aeruginosa. Three bacterial strains utilizing paracetamol as the sole carbon, nitrogen, and energy source were isolated from a paracetamoldegrading aerobic aggregate and assigned to species of the genera Stenotrophomonas and Pseudomonas. The Stenotrophomonas species have not included any known paracetamol degraders until now. In batch cultures, the organisms $\mathrm{f1}, \mathrm{f} 2$, and fg-2 could perform complete degradation of paracetamol at concentrations of $400,2,500$, and $2,000 \mathrm{mg} / \mathrm{L}$ or below, respectively (Zhang et al. 2012). Zhang (2012) also reported that a combination of the three microbial strains recovered from the same culture was shown to be necessary for complete paracetamol degradation and mineralization, suggesting a possible complementary interaction among the various isolates.

Under aerobic conditions, Pseudomonas sp. is capable to utilize aromatic compounds as carbon energy source (Ahmed et al. 1999). The versatility of Pseudomonas makes it an attractive organism for its use in waste treatment application where wide ranges of organic substances are present. The Pseudomonas sp.

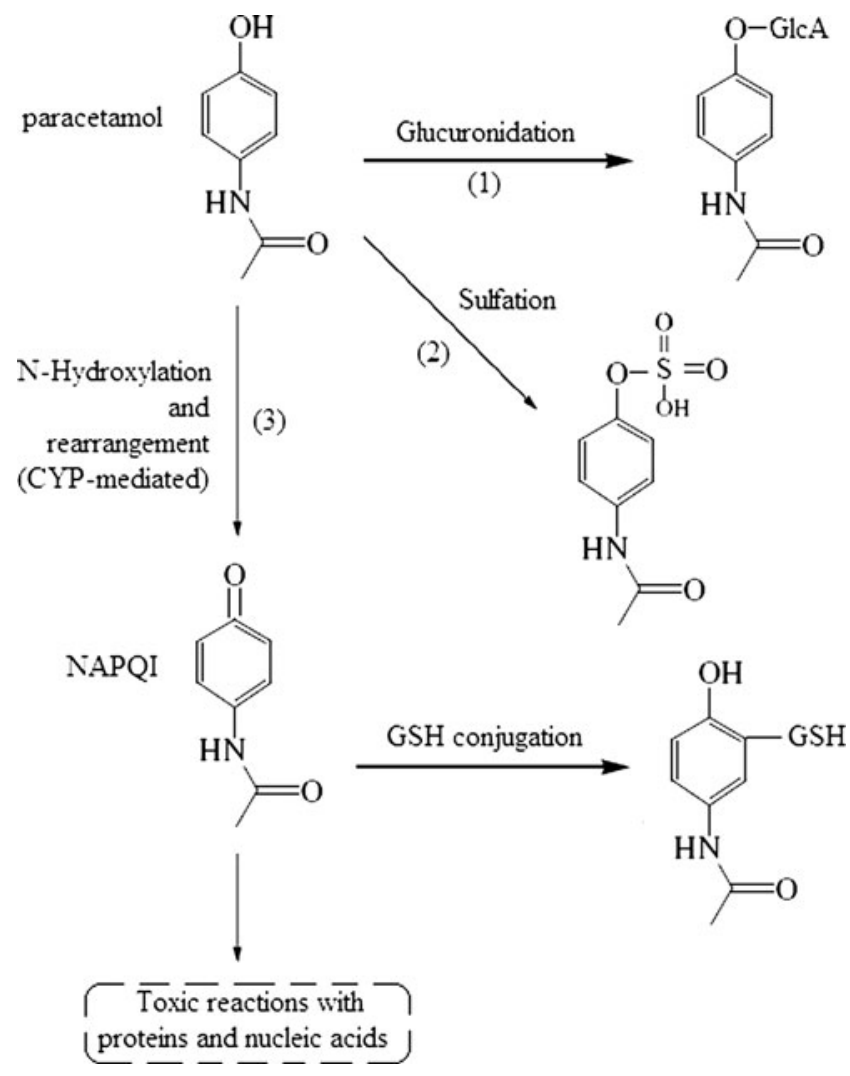

Fig. 2 Main pathways of paracetamol metabolism in animals 
strain ST-4 was adapted to different concentrations of 4aminophenol from 50 to 500 ppm (Sumera et al. 2006). Pseudomonas strain AP-3 had been reported about growth on 2-aminophenol (Takenaka et al. 1997). Aromatic amines have always been related with the property of autoxidation. Actually, these compounds are highly sensitive towards light and temperature, and their continuous exposure to intense heat and light causes their oxidation. The rate of autoxidation was studied at different concentrations. The results showed that a very low rate of autoxidation occurred during the course of experiment. Evaporation and autoxidation are proved to be minor elimination mechanisms removing $1 \%$ of the added aniline/day. Instantaneous binding to the humic components removed $4 \%$. Biodegradation was clearly the most significant removal method to eliminate aniline from aquatic environment. It had also been declared that, although the properties of the autoxidation do exist among the aromatic amines, but the rate was much lower than that of the degradation rate by microbes.

\section{Proposed metabolic pathways, enzymes, and possible intermediates}

During the past decades, research related to paracetamol biodegradation has focused on the identification and characterization of metabolic intermediates involved in the initial step of aerobic bacterial catabolic pathways. Most of the large amounts of investigations regarding metabolic pathways of paracetamol have of course been performed in (laboratory) animals. In animals, paracetamol is metabolized primarily in the liver into nontoxic products. Three metabolic pathways are notable: (1) glucuronidation is believed to account for $40 \%$ to two thirds of the metabolism of paracetamol; (2) sulfation (sulfate conjugation) may account for 20-40\%; (3) $N$-hydroxylation and rearrangement, then GSH conjugation, account for less than $15 \%$. The hepatic cytochrome P450 enzyme system metabolizes paracetamol, forming a minor yet significant alkylating metabolite known as $N$-acetyl- $p$-benzoquinone imine. NAPQI is then irreversibly conjugated with the sulfhydryl groups of glutathione
Fig. 3 Proposed metabolic pathways of paracetamol in man and experimental animals. The individual metabolites were all detected in the urine of organisms that ingested paracetamol in therapeutic quantities (man) (P450 cytochrome P450, NAT N-acetyltransferase, $S T$ sulfotransferase, UDPGT uridine

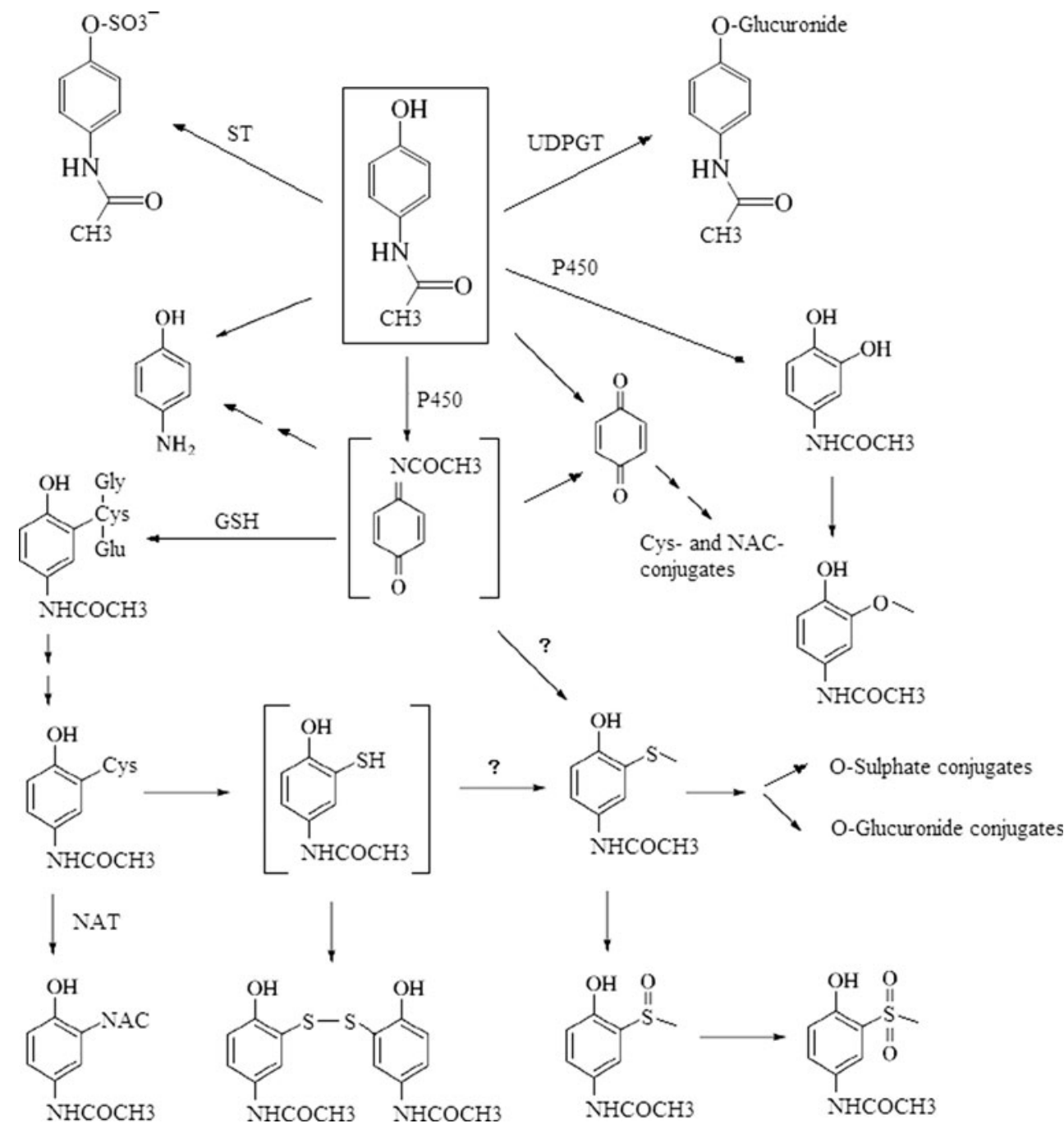


(see Fig. 2). As Thomas reported, paracetamol is metabolized primarily by glucuronidation and sulfation. About 30 and $55 \%$ of administered paracetamol (PAR) is excreted in urine as conjugates PAR-sulfate and PAR-glucuronide, respectively (Thomas 1993). Like in various laboratory animals, a small amount of PAR is probably metabolized via a third metabolic pathway, that is, oxidation by the microsomal cytochrome P450 (CYP)-containing mixed function oxidase system to NAPQI. A glutathione 1,4-Michael adduct of NAPQI and the corresponding cysteine conjugate and mercapturic acid breakdown products were found in human urine after ingestion of PAR (Prescott 1980). A composition of the metabolic pathways of paracetamol in man and experimental animals is depicted in Fig. 3.

With different animals, in most described cases, paracetamol conversion in microbes was proposed to proceed via 4-aminophenol to hydroquinone, which is the major route in biodegradation. Paracetamol is converted to the corresponding 1,4-benzenediol or hydroquinone compounds, i.e., hydroquinone pathway. The paracetamol is initially catalyzed by an amidohydrolase with the release of acetate to yield 4-aminophenol, in which the amino group is then replaced by a hydroxyl group to form hydroquinone, subsequent to ring fission (Fig. 4, steps 1 and 3). In the second instance, the initial hydroxylation of paracetamol could potentially be catalyzed by a hydrolytic enzyme to produce hydroquinone with a release of acetamide, which could be further converted into oxamic acid (Zhang et al. 2012) (Fig. 4, step 2). However, pyrocatechol pathway has also been described by Wei et al. (2011). The identified metabolites suggested another possible main route for paracetamol metabolism (Wei et al. 2011). In the initial reaction, the paracetamol is oxidized by hydroxylase and yields the corresponding $\mathrm{N}$-(4-hydroxyphenyl)-acetamide as the first metabolites in which acetyl group was replaced by hydrogen atom to form $p$-aminophenol (Fig. 4, step 5), and then the $N$ (4-hydroxyphenyl)-acetamide is oxidized to the pyrocatechol by substrate-specific oxygenase and formamide CGTase (Fig. 4, steps 8 and 10). Another route may be similar to hydroquinone pathway. Subsequent oxidation of $\mathrm{N}$-(4-hydroxyphenyl)-acetamide leads to the formation of the hydroquinone and 1,4-benzoquinone that is subsequent to ring fission substrate $p$-phenol, which finally participated in TCA cycles (Fig. 4, steps 6 and 9). Hydroquinone and pyrocatechol pathways were proposed as Fig. 4. Burkholderia sp. strain AK-5 could possibly transform 4-aminophenol to 1,2,4-trihydroxybenzene via 1,4-benzenediol. 1,2,4-Trihydroxybenzene 1,2-dioxygenase cleaved the benzene ring
Fig. 4 Proposed pathway for biodegradation of paracetamol and the enzymes involved. 1 amidohydrolase, 2 hydrolytic enzyme, 3 amino acid oxidase, 4 monooxygenase, 5

hydroxylase, 6 amidohydrolase, 7 hydrolytic enzyme, 8 oxygenase, 9 laccase, 10 formamide CGTase

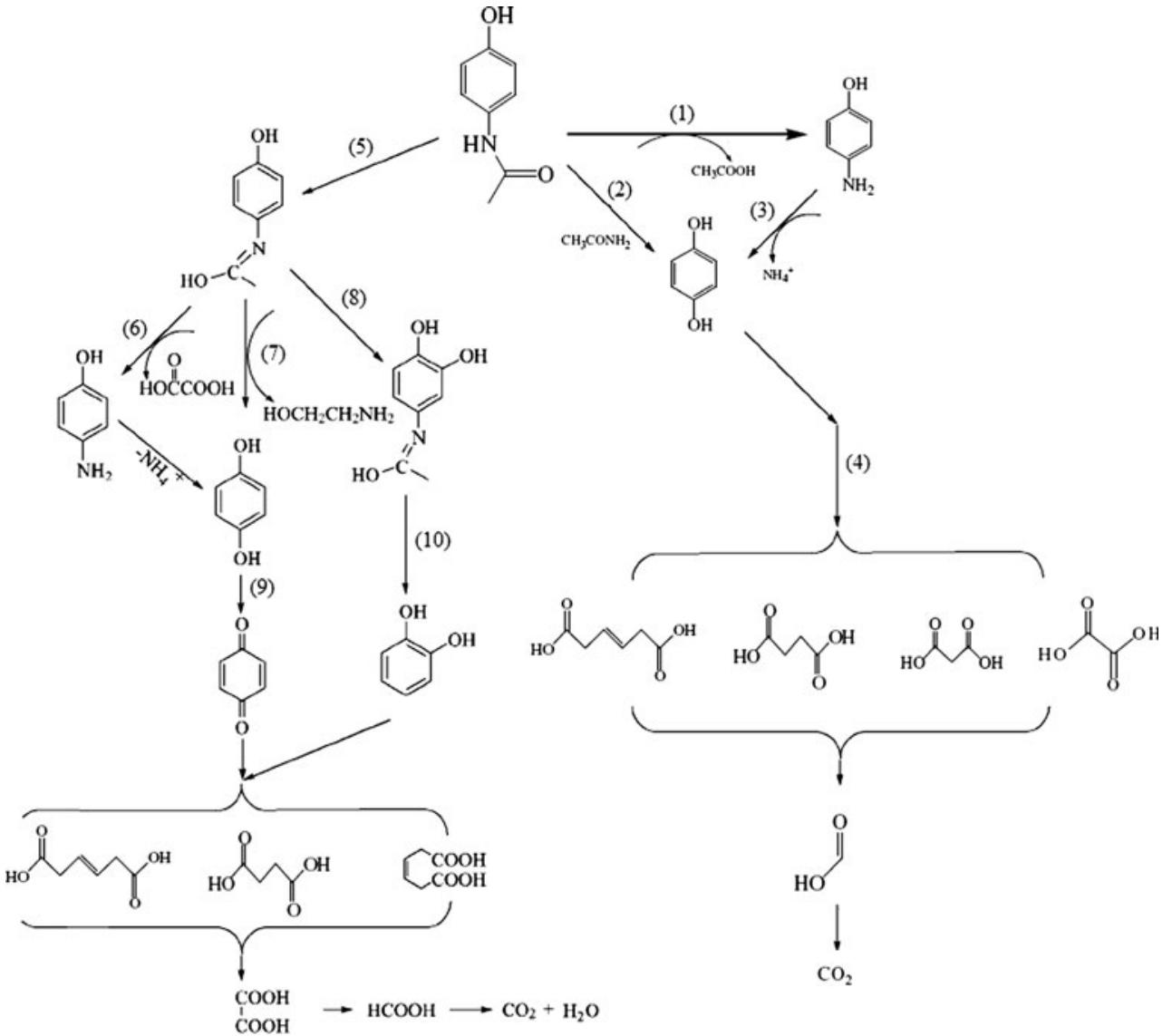

(a) pyrocatechol pathway (b) hydroquinone pathway 
Fig. 5 Proposed pathway of 4aminophenol metabolism in Burkholderia sp. strain AK-5 and comparison to the metabolic pathways of aniline and aniline derivatives. a Proposed pathway of 4-aminophenol metabolism; b metabolic pathways of aniline and aniline derivatives in P. putida 2NP8; c proposed reaction pathways during photocatalytic degradation of paracetamol (a)

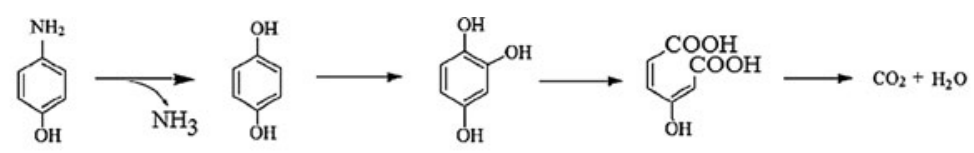

(b)

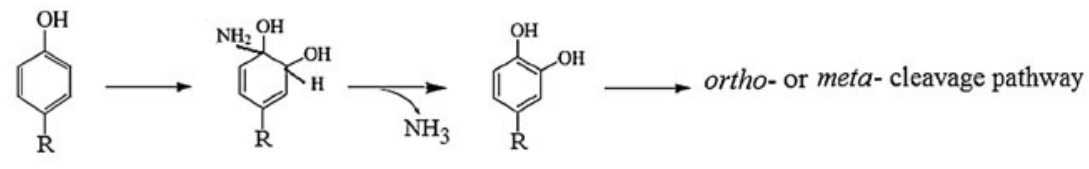

(C)

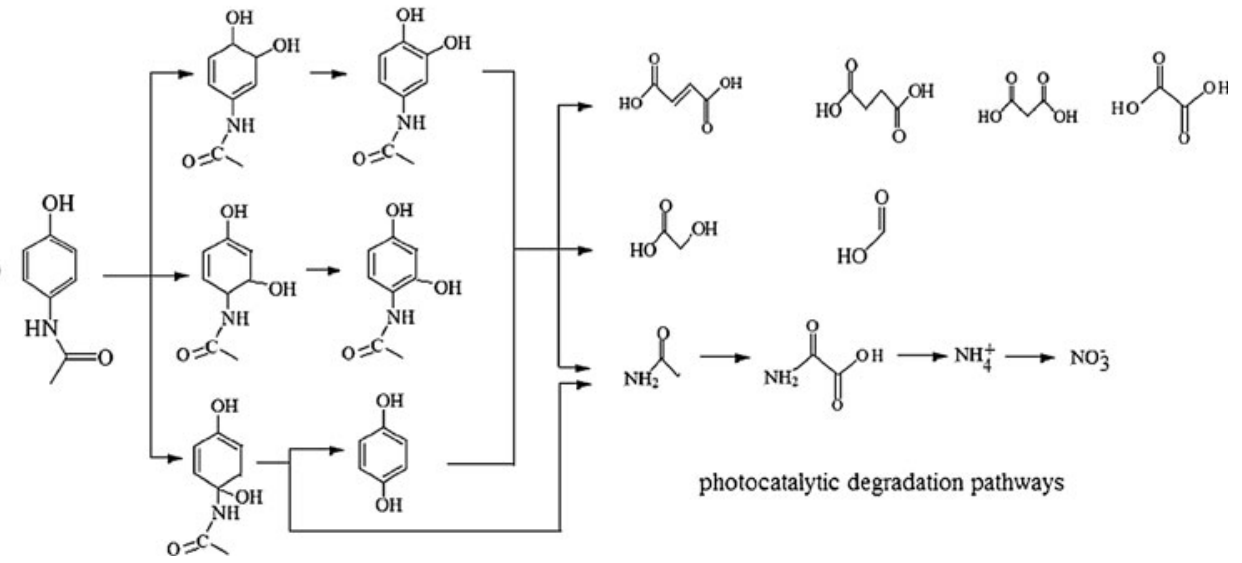

of 1,2,4-trihydroxybenzene to form maleylacetic acid (Murakami et al. 2003). Figure 5a shows the proposed metabolic pathway of 4-aminophenol in strain AK-5. 4Aminophenol was converted to 1,2,4-trihydroxybenzene via 1,4-benzenediol; 1,2,4-trihydroxybenzene 1,2-dioxygenase catalyzed the conversion of 1,2,4-trihydroxybenzene to maleylacetic acid. Presumably, the benzene ring of 4aminophenol is subjected to two hydroxylation steps to yield 1,2,4-trihydroxybenzene. The proposed pathway differs from previously reported metabolic pathways for aniline and anilines with a methyl-, chloro-, sulfo-, or carboxyfunctional-group substituent at the $\mathrm{C}-4$ position

Table 3 Identified intermediates during hydroquinone-degrading pathway of paracetamol using GC-MS and IC analysis

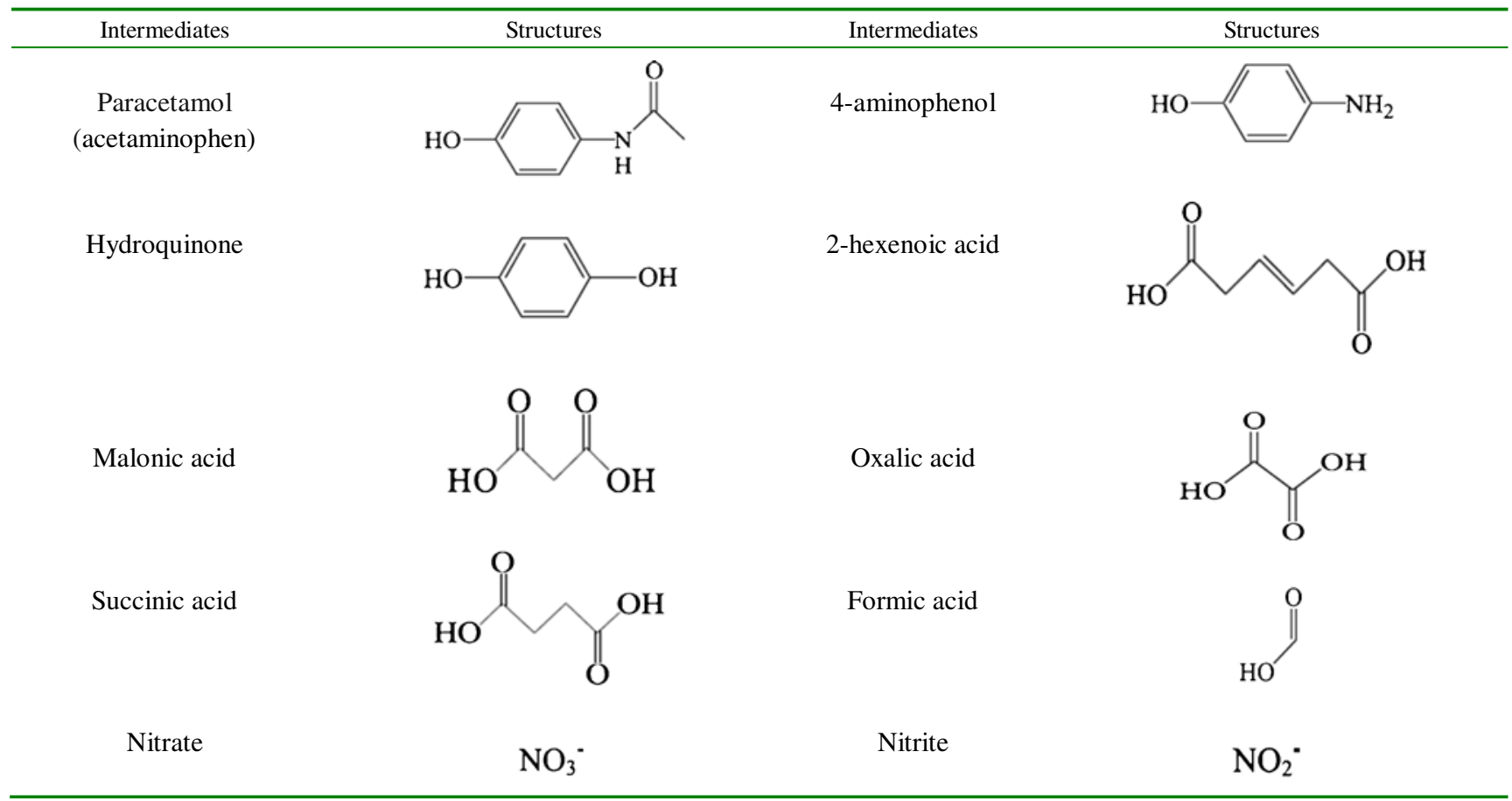


(Fig. 5b) (Zhao et al. 2000; Hughes et al. 2002). The initial reaction in the degradation of anilines is catalyzed by a dioxygenase and yields the corresponding 1-amino-2-hydrodiols as the first metabolites. Subsequent oxidation of 1-amino-2hydrodiols leads to the formation of the catechols. The dioxygenation and dehydrogenation steps to form catechols in these species are similar irrespective of which functional group at the C-4 position of aniline is the electron donor or electron acceptor. P. putida strain TW3 utilized 4-hydroxylaminobenzoate lyase-oxidized 4-hydroxylaminobenzoate to protocatechuate, replacing the amino group by a hydroxyl group (Hughes et al. 2002). Following the aromatic compounds, some carboxylic acids were detected by gas chromatography-mass spectrometry (GC-MS) and immediate constituent (IC) analysis, suggesting that the aromatic compounds can be the precursors of the carboxylic acids. To our knowledge, this is the first description of the biodegradation pathway for paracetamol. The initial steps are partially different from the reactions previously described for photocatalytic and electro-Fenton degradation of paracetamol (Brillas et al. 2009; Yang et al. 2009) (Fig. 5c), in which hydroquinone has been identified as the main transformation products. Gusseme et al. (2011) also reported that hydroquinone was a temporary transformation product of paracetamol degradation by two bacterial strains, D. tsuruhatensis and P. aeruginosa.

Hydroquinone pathway is the major route in paracetamol biodegradation. The metabolites of the initial steps in the paracetamol catabolic pathway were conclusively identified as 4-aminophenol and hydroquinone by GC-MS and HPLCMS (Zhang et al. 2012). The main metabolic intermediates and some carboxylic acids and inorganics were determined by GC-MS and IC analysis, as listed in Table 3. During biodegradation of paracetamol (MSM, initial concentration $500 \mathrm{mg} / \mathrm{L}, 28^{\circ} \mathrm{C}, 2 \mathrm{~h}, \mathrm{pH} 7.2$ ), a total of ten intermediates were identified. According to base structures of individual molecules, identified intermediates are categorized into four classes: (1) three aromatic compounds; (2) carboxylic acids, including five saturated and one unsaturated carboxylic acid; (3) nitrogen-containing straight chain compounds, including oxamic acid and acetamide; and (4) inorganics (ammonium and nitrate). Based on concentration profiles of identified intermediates during initial reaction stages (within $100 \mathrm{~min}$ ), paracetamol mainly undergoes hydroxylation through $\mathrm{OH}$ addition onto the aromatic ring at para position with respect to the hydroxyl $(-\mathrm{OH})$ group of paracetamol, as pathways shown in Fig. 2.

In contrast, in pyrocatechol pathway, as Wei et al. (2011) reported, acetyl group was replaced by hydrogen atom to form $p$-aminophenol as the first degradation product, and then $p$ aminophenol was further converted to the ring fission substrate $p$-phenol. Compounds 1 and 2 presented mass spectra with two major ions at $\mathrm{m} / \mathrm{z} 108$ and 109 , which corresponded to a molecular mass $[\mathrm{M}-\mathrm{H}]^{-}$of 4 -aminophenol and hydroquinone, respectively. Pyrocatechol and 2-aminoethanol were obtained by comparison of their mass spectrum with that of authentic derivatized compound. 4-Aminophenol was also indentified as a main intermediate during photocatalytic degradation of paracetamol (Yang et al. 2009). Following formation of the three aromatic compounds, concentrations of carboxylic acids peaked around $270 \mathrm{~min}$, suggesting that the three aromatic compounds can be precursors of the five carboxylic acids (Fig. 5) through cleavage of benzene rings and further biodegradation. While most intermediates exhibited a peak concentration, oxamic acid, ammonium, and nitrate continually increased in concentration throughout the reaction (up to $450 \mathrm{~min}$ ), indicating continuous mineralization of nitrogen-containing intermediates. As suggested in pathway in Fig. 5c, oxamic acid can be formed through $\mathrm{OH}$ oxidation of acetamide after initial oxidation of paracetamol.

\section{References}

Ahmed Z, Sarwar Z, Ahmad N, Hussain MS, Riazuddin S (1999) Genetic modification of Pseudomonas putida for enhanced degradation of phenol and nitrophenol. Pak J Biochem Mol Bio 32:32-37

Andreozzi R, Caprio V, Marotta R, Vogna D (2003) Paracetamol oxidation from aqueous solutions by means of ozonation and $\mathrm{H}_{2} \mathrm{O}_{2} /$ UV system. Water Res 37(5):993-1004

Bales JR, Nicholson JK, Sadler PJ (1985) Two-dimensional proton nuclear magnetic resonance maps of acetaminophen metabolites in human urine. Clin Chem 31(5):757-762

Bart DG, Lynn V, Willy V, Nico B (2011) Degradation of acetaminophen by Delftia tsuruhatensis and Pseudomonas aeruginosa in a membrane bioreactor. Water Res 45:1829-1837

Bedner M, Maccrehan WA (2006) Transformation of acetaminophen by chlorination produces the toxicants 1,4-benzoquinone and $\mathrm{N}$ acetyl-p-benzoquinone imine. Environ Sci Technol 40:516-522

Benotti MJ, Trenholm RA, Vanderford BJ, Holady JC, Stanford BD, Snyder SA (2009) Pharmaceuticals and endocrine disrupting compounds in U.S. drinking water. Environ Sci Technol 43:597-603

Bessems JGM, Vermeulen NPE (2001) Paracetamol (acetaminophen)induced toxicity: molecular and biochemical mechanisms, analogues and protective approached. Crit Rev Toxicol 31:55-138

Betz JL, Clarke PH (1973) Growth of Pseudomonas species on phenylacetamide. J Gen Microbiol 75:167-177

Bound JP, Voulvoulis N (2006) Predicted and measured concentrations for selected pharmaceuticals in UK rivers: implications for risk assessment. Water Res 40:2885-2892

Boyd RA, Furlong ET (2002) Human-health pharmaceutical compounds in Lake Mead, Nevada and Arizona, and Las Vegas Wash, Nevada, October 2000-August 2001. US Geological Survey, Reston, pp 1-18

Brillas E, Sirés I, Arias C, Cabot PL, Centellas F, Rodríguez RM, Garrido JA (2005) Mineralization of paracetamol in aqueous medium by anodic oxidation with a boron-doped diamond electrode. Chemosphere 58(4):399-406

Brillas E, Sirés I, Oturan MA (2009) Electro-Fenton process and related electrochemical technologies based on Fenton's reaction chemistry. Chem Rev 109:6570-6631

Brun GL, Bernier M, Losier R, Doe K, Jackman P, Lee HB (2006) Pharmaceutically active compounds in Atlantic Canadian 
sewage treatment plant effluents and receiving waters, and potential for environmental effects as measured by acute and chronic aquatic toxicity. Environ Toxicol Chem 25(8):21632176

Chen CY, Chen SC, Fingas M, Kao CM (2010) Biodegradation of propionitrile by Klebsiella oxytoca immobilized in alginate and cellulose triacetate gel. J Hazard Mat 177:856-863

Escher BI, Baumgartner R, Koller M, Treyer K, Lienert J, McArdell CS (2011) Environmental toxicology and risk assessment of pharmaceuticals from hospital wastewater. Water Res 45:7592

Gomez MJ, Bueno MJM, Lacorte S, Fernandez-Alba AR, Aguera A (2007) Pilot survey monitoring pharmaceuticals and related compounds in a sewage treatment plant located on the Mediterranean coast. Chemosphere 66(6):993-1002

Gros M, Petrovic M, Barcelo D (2006) Development of a multi-residue analytical methodology based on liquid chromatography-tandem mass spectrometry (LC-MS/MS) for screening and trace level determination of pharmaceuticals in surface and wastewaters. Talanta 70:678-690

Gusseme BD, Vanhaecke L, Verstraete W, Boon N (2011) Degradation of acetaminophen by Delftia tsuruhatensis and Pseudomonas aeruginosa in a membrane bioreactor. Water Res 45:1829-1837

Han GH, Hur HG, Kim SD (2006) Ecotoxicological risk of pharmaceuticals from wastewater treatment plants in Korea: occurrence and toxicity to Daphnia magna. Environ Toxicol Chem 25 (1):265-271

Hart A, Orr DLJ (1975) The degradation of paracetamol (4-hydroxyacetanilide) and other substituted acetanilides by a Penicillium species. Anton van Leeuw 41:239-247

Hasan SA, Ferreira MIM, Koetsier MJ, Arif MI, Janssen DB (2011) Complete biodegradation of 4-fluorocinnamic acid by a consortium comprising Arithrobacter sp. strain G1 and Ralstonia sp. strain H1. Appl Environ Microbiol 77(2):572-579

Hu J, Zhou L, Zhou QW, Wei F, Zhang LL, Chen JM (2012) Biodegradation of paracetamol by aerobic granules in a sequencing batch reactor (SBR). Adv Mater Res 441:531-535

Huber MM, Göbel A, Joss A, Hermann N, Löffler D, Mcardell CS, Ried A, Siegrist H, Ternes TA, Gunten UV (2005) Oxidation of pharmaceuticals during ozonation of municipal wastewater effluents: a pilot study. Environ Sci Technol 39:4290-4299

Hughes MA, Baggs MJ, Al-Dulayymi J, Baird MS, Williams PA (2002) Accumulation of 2-aminophenoxazin-3-one-7-carboxylate during growth of Pseudomonas putida TW3 on 4-nitrosubstituted substrates requires 4-hydroxylaminobenzoate lyase (PnbB). Appl Environ Microbiol 68:4965-4970

Jones AL (1998) Mechanism of action and value of $N$-acetylcysteine in the treatment of early and late acetaminophen poisoning: a critical review. Clin Toxicol 36:277-285

Jones OAH, Voulvoulis N, Lester JN (2007) The occurrence and removal of selected pharmaceutical compounds in a sewage treatment works utilizing activated sludge treatment. Environ Pollut 145:738-744

Kolpin DW, Furlong ET, Meyer MT, Thurman EM, Zaugg SD, Barber LB, Buxton HT (2002) Pharmaceuticals, hormones, and other organic wastewater contaminants in U.S. streams, 19992000: a national reconnaissance. Environ Sci Technol 36 (6):1202-1211

Langford KH, Thomas KV (2009) Determination of pharmaceutical compounds in hospital effluents and their contribution to wastewater treatment works. Environ Int 25:766-770

Li TG, Liu JX, Bai RB, Ohandja DG, Wong FS (2007) Biodegradation of organonitriles by adapted activated sludge consortium with acetonitrile-degrading microorganisms. Water Res 41:3465-3473
Malmberg AB, Yaksh TL (1982) Hyperalgesia mediated by spinal glutamate or substance P receptor blocked by spinal cyclooxygenase inhibition. Science 257:1276-1279

Muir N, Nichols JD, Stillings MR, Sykes J (1997) Comparative bioavailability of aspirin and paracetamol following single dose administration of soluble and plain tablets. Curr Med Res Opin 13(9):491-500

Murakami S, Aoki K, Takenake S, Okugawa S, Kadowaki M (2003) The metabolic pathway of 4-aminophenol in Burkholderia sp. strain AK-5 differs from that of aniline and aniline with C-4 substituents. Appl Environ Microbiol 69(9):5410-5412

Petrovic M, Gonzalez S, Barceló D (2003) Analysis and removal of emerging contaminants in wastewater and drinking water. Trends Anal Chem 22:685-696

Philips PJ, Smith SG, Koplin DW, Zaugg SD, Buxton HT, Furlong ET, Esposito K, Stinson B (2010) Pharmaceutical formulation facilities as sources of opioids and other pharmaceuticals to wastewater treatment plant effluents. Environ Sci Technol 44:4910-4916

Prescott LF (1980) Kinetics and metabolism of paracetamol and phenacetin. Br J Clin Pharmacol 10:291S-298S

Radjenovic J, Petrovic M, Barcelo D (2007) Analysis of pharmaceuticals in wastewater and removal using a membrane bioreactor. Anal Bioanal Chem 387:1365-1377

Robert PH, Thomas KV (2006) The occurrence of selected pharmaceuticals in wastewater effluent and surface waters of the lower Tyne catchment. Sci Total Environ 356(1-3):143-153

Sebastine IM, Wakeman RJ (2003) Consumption and environmental hazards of pharmaceutical substances in the UK. Process Saf Environ Prot 81(84):229-235

Sheen L, Dillon JF, Bateman DN, Simpson KJ, Macdonald TM (2002) Paracetamol toxicity: epidemiology, prevention and costs to the health-care system. QJM 95:609-619

Skoumal M, Cabot PL, Centellas F, Arias C, Rodríguez RM, Garrido JA, Brillas E (2006) Mineralization of paracetamol by ozonation catalyzed with $\mathrm{Fe}^{2+}, \mathrm{CU}^{2+}$ and UVA light. Appl Catal B: Environ 66:228-240

Stackelberg PE, Furlong ET, Meyer MT, Zaugg SD, Henderson AK, Reissman DB (2004) Persistence of pharmaceutical compounds and other organic wastewater contaminants in a conventional drinking water treatment plant. Sci Total Environ 329:99-113

Sumera AK, Muhammad H, Safia A (2006) Degradation of 4aminophenol by newly isolated Pseudomonas sp. strain ST-4. Enzyme Microb Technol 38:10-13

Takenaka S, Murakami S, Shinke R, Hatakeyama K, Yukawa H, Aoki K (1997) Novel genes encoding 2-aminophenol 1,6 dioxygenase from Pseudomonas species strain AP-3 growing on 2-aminophenol, and catalytic properties of the purified enzyme. J Biol Chem 1272:14727-14732

Ternes TA (1998) Occurrence of drugs in German sewage treatment plants and rivers. Water Res 32:3245-3260

Thomas SH (1993) Paracetamol (acetaminophen) poisoning. Pharmacol Ther 60:91-120

Thomas, KV, Langford KH (2007) Occurrence of pharmaceuticals in the aqueous environment. Petrovic M, Barcelo D (eds) Analysis, fate and removal of pharmaceuticals in the water cycle. Wilson \& Wilson's Comprehensive Analytical Chemistry series, Elsevier, Chapter 3:341-363

Thomas KV, Dye C, Schlabach M, Langford KH (2007) Source to sink tracking of selected human pharmaceuticals from two Oslo city hospitals and a wastewater treatment works. J Environ Monit 9 (12):1410-1418

Verlicchi P, Galletti A, Petrovic M, Barceló D (2010) Hospital effluents as a source of emerging pollutants: an overview of micropollutants and sustainable treatment options. J Hydrol 389:416-428 
Wei F, Zhou QW, Leng SQ, Zhang LL, Chen JM (2011) Isolation, identification and biodegradation characteristics of a new bacterial strain degrading paracetamol. Environ Sci 32:1813-1819

Wiegel S, Aulinger A, Brockmeyer R, Harms H, Loffler J, Reincke H, Schmidt R, Stachel B, von Tumpling W, Wanke A (2004) Pharmaceuticals in the river Elbe and its tributaries. Chemosphere 57:107-126

Xu MY, Zen GQ, Cai XW, Sun GP (2003) Screening of high efficient paracetamolum degrading bacterial strains and the effect of their bioaugmentative use. Acta Sci Circumstantiae 23:391-395

Yang LM, Yu LE, Ray MB (2008) Degradation of paracetamol in aqueous solutions by $\mathrm{TiO} 2$ photocatalysis. Water Res 42:2480 2488
Yang LM, Yu LE, Ray MB (2009) Photocatalytic oxidation of paracetamol: dominant reactants, intermediates, and reaction mechanisms. Environ Sci Technol 43:460-465

Zhao JS, Singh A, Huang XD, Ward OP (2000) Biotransformation of hydroxylamine and aminophenol by Pseudomonas putida 2NP8 cells grown in the presence of 3-nitrophenol. Appl Environ Microbiol 66:2336-2342

Zhang X, Wu F, Wu XW, Chen PY, Deng NS (2008) Photodegradation of acetaminophen in $\mathrm{TiO} 2$ suspended solution. J Hazard Mater 157(2-3):300-307

Zhang LL, Hu J, Zhu RY, Zhou QW, Chen JM (2012) Degradation of paracetamol by pure bacterial cultures and their microbial consortium. Appl Microbiol Biotechnol. doi:10.1007/s00253-012-4170-5 